AperTO - Archivio Istituzionale Open Access dell'Università di Torino

Human flavin-containing monooxygenase 1 and its long-sought hydroperoxyflavin intermediate

This is a pre print version of the following article:

Original Citation:

Availability:

This version is available http://hdl.handle.net/2318/1806342

since 2021-09-28T14:41:56Z

Published version:

DOI:10.1016/j.bcp.2021.114763

Terms of use:

Open Access

Anyone can freely access the full text of works made available as "Open Access". Works made available under a Creative Commons license can be used according to the terms and conditions of said license. Use of all other works requires consent of the right holder (author or publisher) if not exempted from copyright protection by the applicable law. 


\title{
Biochemical Pharmacology
}

Volume 193, November 2021, 114763

\section{Human flavin-containing monooxygenase 1 and its long-sought hydroperoxyflavin intermediate}

\author{
Hanna Cheropkina $\dagger^{\mathrm{a}}$, Gianluca Catucci $\dagger^{\mathrm{a}}$, Arianna Marucco ${ }^{\mathrm{a}}$, Ivana Fenoglio ${ }^{\mathrm{b}}$, \\ Gianfranco Gilardia and Sheila J. Sadeghia*
}

a Department of Life Sciences and Systems Biology, University of Torino, Italy;

${ }^{b}$ Department of Chemistry, University of Torino, Italy.

† These authors contributed equally to this work.

* Corresponding author: Department of Life Sciences and Systems Biology, Via Accademia Albertina 13, 10123 Torino, Italy.

Tel.: +39 0116704528 ;

Fax: +390116704643.

E-mail address: sheila.sadeghi@unito.it

\section{Category:}

Pharmacokinetics and Drug Metabolism 


\section{Abstract}

Out of the five isoforms of human flavin-containing monooxygenase (hFMO), FMO1 and FMO3 are the most relevant to Phase I drug metabolism. They are involved in the oxygenation of xenobiotics including drugs and pesticides using NADPH and FAD as cofactors. Majority of the characterization of these enzymes has involved hFMO3, where intermediates of its catalytic cycle have been described. On the other hand, research efforts have so far failed in capturing the same key intermediate that is responsible for the monooxygenation activity of hFMO1. In this work we demonstrate spectrophotometrically the formation of a highly stable C4ahydroperoxyflavin intermediate of hFMO1 upon reduction by NADPH and in the presence of $\mathrm{O}_{2}$. The measured half-life of this flavin intermediate revealed it to be stable and not fully reoxidized even after 30 minutes at $15{ }^{\circ} \mathrm{C}$ in the absence of substrate, the highest stability ever observed for a human FMO. In addition, the uncoupling reactions of hFMO1 show that this enzyme is $<1 \%$ uncoupled in the presence of substrate, forming small amounts of $\mathrm{H}_{2} \mathrm{O}_{2}$ with no observable superoxide as confirmed by EPR spin trapping experiments. This behaviour is different from hFMO3, that is shown to form both $\mathrm{H}_{2} \mathrm{O}_{2}$ and superoxide anion radical as a result of $\sim 50 \%$ uncoupling. These data are consistent with the higher stability of the hFMO1 intermediate in comparison to hFMO3. Taken together, these data demonstrate the different behaviours of these two closely related enzymes with consequences for drug metabolism as well as possible toxicity due to reactive oxygen species.

Keywords: flavin-containing monooxygenase, ROS, drug metabolism, Stopped-flow, Spectroscopy, uncoupling. 


\section{Introduction}

Phase I drug metabolism involves monooxygenase enzymes that are able to split the two atoms of molecular oxygen with insertion of one of them in a stable, often unreactive, carbon atom or a heteroatom (sulphur or nitrogen) of the substrate (drug) with concomitant production of a water molecule [1-4].

The catalytic cycle of these enzymes involves the formation of an oxygen reactive intermediate that is of a different nature depending on the cofactor present in the enzyme. In cytochromes P450, the most studied monooxygenases, this intermediate consists in an oxyferryl intermediate of the haem cofactor. This intermediate has been spectroscopically identified [5] and in some cases characterised by trapping techniques and cryocrystallography $[6,7]$. As for other most studied monooxygenase, flavin-containing monooxygenases (FMOs), the C4ahydroperoxyflavin intermediate of the FAD is responsible for the heteroatom oxidation of the substrate, and to this date it has been spectroscopically characterised for the bacterial FMO [8], isoform-3 of the human enzyme (hFMO3) [9] and the isoform-1 of pig (pFMO1) [10-13]. The lifetime of these intermediates is very different, the pFMO1 lasting in the hour timescale, while $\mathrm{hFMO} 3$ lasts for minutes at $15{ }^{\circ} \mathrm{C}[9,11]$. The lifetime of this reactive intermediate is a very important parameter because it has relevant consequences on the catalytic performance of the enzyme. Indeed, the catalytic cycle of the FMO enzymes involves the formation of the reactive intermediate prior to substrate binding. As a consequence, a short-lived intermediate risks to

promote the formation of hydrogen peroxide or superoxide, uncoupling the consumption of reducing units and oxygen from the formation of the oxidised product [13-15]. On the other hand, a long-lived intermediate results in highly coupled enzymes. 
Beaty and Ballou provided the first evidence of the reaction mechanism of FMOs in the 1980s $[10,11]$. In a remarkable reference work for the field, it was shown how pFMO1 was initially reduced by NADPH followed by binding of molecular oxygen and stabilization of a long-lived hydroperoxy-intermediate [11] that still today is ascribed as the moiety responsible for catalysis. As mentioned above, the stopped-flow experiments of Beaty and Ballou were performed using the pFMO1 [11], but five different FMO genes are present in humans [16-17]. The most relevant isoforms for drug metabolism are FMO1 and FMO3 that are also polymorphic [18-21]. In the last 40 years bioinformatics and recombinant DNA technology has allowed for the designing of clones and the subsequent heterologous expression of FMOs in bacterial hosts such as E. coli [22]. More recently it has been shown that $\mathrm{hFMO3,} \mathrm{that} \mathrm{for} \mathrm{a} \mathrm{long} \mathrm{time} \mathrm{was} \mathrm{thought} \mathrm{to} \mathrm{behave}$ like pFMO1, only transiently binds the substrate [23]. Stopped-flow experiments demonstrated that hFMO3 forms and stabilizes only a small amount of intermediate in the presence of oxygen that rapidly decays [24]. A role for $\mathrm{NADP}^{+}$in the stabilization of the intermediate and the overall structure of this enzyme was also demonstrated $[24,25]$.

The real physiological substrate of hFMO1 was only discovered recently. The research group of Shephard used metabolite analysis by ${ }^{1} \mathrm{H}$ NMR spectroscopy to decipher the role of hFMO1 in the biosynthetic pathway of taurine using hypotaurine as its substrate [26]. Taurine, a highly abundant amino acid in humans, can be synthesized de novo from hypotaurine. Furthermore, they also demonstrated the $\mathrm{pH}$ dependent ability of $\mathrm{hFMO} 1$ to use either $\mathrm{NADH}$ or NADPH as reducing cofactor [26].

As the chemical nature of the C4a-hydroperoxyflavin intermediate is the same in all the FMO enzymes, its lifetime and therefore reactivity is modulated by the protein environment. Two different approaches can be followed; (1) resolving the crystal structure and looking at the protein matrix surrounding the flavin cofactor to justify any differences observed in the catalytic 
activity of different FMOs and/or (2) investigate the formation and decay of the FAD intermediate by spectroscopy. Regarding the first option, to date no 3D structure of any human FMO has been resolved since they are membrane-bound proteins and not stable in aqueous environment [27]. Association to membrane is a well-known hinderance to the general crystallization process of proteins. To overcome this obstacle, synthetic genes coding for ancestral FMO isoforms and in particular the FMO1 was recently synthesized and the resulting synthetic protein was crystalized [28]. In this work the second option was followed in order to investigate the reactivity of this intermediate in hFMO1 and compare its behaviour to other human FMOs as well as its homologous counterpart, pFMO1. To this end, this work reports on the investigation of the formation and the stability of the C4a-hydroperoxyflavin intermediate of hFMO1 by stopped-flow spectroscopy and the consequences for the catalytic activity of this enzyme.

\section{Materials and methods}

\subsection{Chemicals}

Chromatographic resins were purchased from GE Healthcare (Italy). Chemicals including Luria Bertani (LB), tryptone, agar, ampicillin, Isopropyl-beta-D-thiogalactopyranoside (IPTG), phenylmethanesulfonylfluoride (PMSF), riboflavin, flavin adenine dinucleotide (FAD), $\beta-$ mercaptoethanol, glycerol, lysozyme, NADPH, NADP ${ }^{+}, \mathrm{NADH}, \mathrm{NAD}^{+}$, hypotaurine, taurine, tamoxifen, fenthion, fenthion sulfoxide, phosphoric acid, acetonitrile, methanol, triethylamine and salts were all purchased from Sigma-Aldrich. Tamoxifen N-oxide standard was purchased from Toronto Research Chemicals (Canada). All chemicals were of highest available purity and used without any further purification. All media, solutions and buffers were prepared with deionized Milli-Q water. 


\subsection{Protein expression and purification}

The hFMO1 gene and the oligonucleotides encoding its amino- and carboxy-termini were synthesized by GeneScript Biotech (Netherlands). The gene was sub-cloned in pJL2 expression vector within the Xbal - Hindlll restriction sites [29]. A stretch of four histidine residues (5' ATGGTGATGGTG 3') was inserted at the C-terminus to assist in the purification. The hFMO1 protein was expressed in Escherichia coli JM109 cells in two-liter conical flasks containing $500 \mathrm{~mL}$ of Terrific Broth (TB). Cells were induced by $1 \mathrm{mM} \mathrm{IPTG}$ and grown at $24^{\circ} \mathrm{C}$ with ampicillin $(100 \mu \mathrm{g} / \mathrm{mL}), 50 \mathrm{mg} / \mathrm{L}$ of riboflavin. After 24 hours post-induction cells were harvested by $20 \mathrm{~min}$ centrifugation at $4000 \mathrm{rpm}$ at $4^{\circ} \mathrm{C}$. The cell pellet was stored at $-20^{\circ} \mathrm{C}$ until use.

The protein was purified from the membrane fractions via DEAE anion-exchange and $\mathrm{Ni}$ chelating sepharose fast-flow affinity column, following the procedure described previously for FMO3 [30]. Briefly, pellet containing hFMO1 was resuspended in Buffer A (50 mM KPi pH 8.0, $20 \%$ glycerol, $5 \mathrm{mM} \beta$-mercaptoethanol) with $0.5 \mathrm{mM} \mathrm{PMSF}$ using $5 \mathrm{ml} / \mathrm{g}$ of cells. This was followed by the addition of $0.5 \mathrm{mg} / \mathrm{ml}$ of lysozyme and the solution was stirred for 1 hour at $4^{\circ} \mathrm{C}$. The cells were then lysed by ultrasonication ( $10 \times 30$ seconds). The resulting lysate was ultracentrifuged at $41,000 \mathrm{rpm}$ for $60 \mathrm{~min}$ at $4^{\circ} \mathrm{C}$. Subsequently, the pellet containing the membrane fraction was resuspended using Dounce homogenizer in Buffer A with $1 \%$ IGEPAL and left stirring for 2 hours at $4^{\circ} \mathrm{C}$. This was followed by a second ultracentrifugation step $\left(41,000 \mathrm{rpm}\right.$ for $60 \mathrm{~min}$ at $\left.4^{\circ} \mathrm{C}\right)$ after which the supernatant was loaded on a DEAE-Sepharose Fast Flow column linked to the affinity chromatography column. Human FMO1 protein was eluted with $40 \mathrm{mM}$ histidine. The elution profile was monitored by UV/Vis spectroscopy and fractions containing the flavoprotein were pooled and buffer exchanged (100 mM KPi pH 8.0, 
$20 \%$ glycerol) using $30 \mathrm{kDa}$ cutoff Amicon ${ }^{\mathrm{TM}}$ Ultra Centrifugal Filter. The purified protein was stored at $-80^{\circ} \mathrm{C}$ in small aliquots to prevent repeated thawing/ freezing.

The concentration and yield of the FMO1 protein were estimated by UV/Vis spectroscopy considering a 1:1 molar content of FAD. The molecular extinction coefficient of $11,300 \mathrm{M}^{-1} \mathrm{~cm}^{-1}$ at $450 \mathrm{~nm}$ was used. Protein purity was verified by separation and visualization in $12 \%$ SDS polyacrylamide gel stained with Coomassie Blue.

\subsection{Circular Dichroism}

The CD spectra of hFMO1 were obtained by a J-815 CD spectrometer (JASCO International Co., Tokyo, Japan). Scans were performed in $0.1 \mathrm{M}$ phosphate buffer $\mathrm{pH} 7.4$ with protein concentration of $3.5 \mu \mathrm{M}$ at $25^{\circ} \mathrm{C}$. Spectral range was from $190 \mathrm{~nm}$ to $260 \mathrm{~nm}$ with the scan rate of $100 \mathrm{~nm} / \mathrm{min}$ using $1 \mathrm{~nm}$ band width in $0.1 \mathrm{~cm}$ path length cell. The protein secondary structure content was estimated by fitting the experimental data to Beta Structure Selection (BeStSel) [31].

\subsection{Differential scanning calorimetry (DSC)}

Investigation of the stabilization effect of cofactor binding to the purified enzyme was characterized by DSC using a Microcal VP-Capillary DSC (Malvern Instruments Ltd. Worcestershire, UK). All scans were performed at a scan rate of $90^{\circ} \mathrm{C} / \mathrm{h}$ in the temperature range from 27 to $90^{\circ} \mathrm{C}$ in $0.1 \mathrm{M}$ phosphate buffer $\mathrm{pH} 7.4$ with a protein concentration of $10 \mu \mathrm{M}$ in the absence or presence of ligand $\left(0.5 \mathrm{mM} \mathrm{NADP}^{+}\right.$or $\left.\mathrm{NAD}^{+}\right)$. Before the experiment, the working cell was pre-equilibrated with 10 cycles of working buffer and followed by another equilibration for $10 \mathrm{~min}$ at $25^{\circ} \mathrm{C}$. According to the procedure, the scan of the working sample was followed by the control rescan to check the absence of refolding process. This latter scan 
was used as the control sample for background correction during the data collection $[9,25]$. Protein melting temperatures and all required deconvolution steps were performed by fitting the data to the Levenberg-Marquardt non-linear least-square method using Origin software within MicroCal package.

\subsection{Rapid kinetics of reductive and re-oxidative half-reactions}

Rapid kinetic experiments were performed using the Hi-Tech scientific SF-61 (single mixing controlled by Kinetic studioV3 software, HI-TECH Scientific, UK) stopped-flow instrument under anaerobic conditions in a glovebox (Belle Technologies, UK). Solutions needed for the analysis were prepared in outgassed $0.1 \mathrm{M}$ phosphate buffer $\mathrm{pH} 7.4$, except where oxygen was required for protein re-oxidation. The protein re-oxidation process was initiated by fully reducing $10 \mu \mathrm{M}$ hFMO1 by 1.2 equivalent of NADPH. Once reduced, the protein solution was subsequently mixed with oxygen saturated buffer with/without hypotaurine solution, as substrate. All reoxidation experiments were carried out at $15^{\circ} \mathrm{C}$. Formation of $\mathrm{C} 4 \mathrm{a}$-(hydro)peroxyflavin intermediate was followed at $368 \mathrm{~nm}$ and the re-oxidized FAD followed by the increase in absorbance at $450 \mathrm{~nm}$.

Reductive half-reaction was monitored in the presence of different NADPH or NADH concentrations by mixing $1: 1 \mathrm{v} / \mathrm{v}$ with protein solution at $15^{\circ} \mathrm{C}$. The rate of the reduction process was estimated by following the absorbance decrease at $450 \mathrm{~nm}$. Both re-oxidation and reduction half-reactions were analyzed by Kinetic Studio Version 5.1.0.6 software and reduction rates with increased ligand concentrations were fitted using non-linear regression analysis using OriginPro 2021. All experiments were carried out in triplicates.

\subsection{Enzyme NADPH consumption assay}


NADPH/NADH consumption by hFMO1 was monitored by Agilent HP-8453E spectrophotometer at $340 \mathrm{~nm}$. Reaction mixtures typically contained: $0.2 \mu \mathrm{M} \mathrm{hFMO1}$ in $0.1 \mathrm{M}$ phosphate buffer $\mathrm{pH} 7.4$ with different concentrations of NADPH/NADH ranging from 0 to 500 $\mu \mathrm{M}$. The reaction was followed for $300 \mathrm{sec}$ at $37^{\circ} \mathrm{C}$. The catalytic activity of hFMO1 was tested in the presence of hypotaurine as a known substrate. Reaction conditions were the same as above with $0.1 \mathrm{mM} \mathrm{NADPH}$ but this time at various concentrations of hypotaurine from 0 to 250 $\mu \mathrm{M}$. The initial velocity was estimated by following the consumption of NADPH at $340 \mathrm{~nm}$ $\left(\varepsilon_{\mathrm{NADPH} / \mathrm{NADH}}=6220 \mathrm{M}^{-1} \mathrm{~cm}^{-1}\right)$. Kinetic parameters $\mathrm{K}_{\mathrm{M}}$ and $\mathrm{k}_{\mathrm{cat}}$ were estimated by fitting the data (five replicates of each data point) with the Michaelis-Menten equation using OriginPro 2021 software.

\subsection{In vitro metabolic assay}

Substrate conversion mediated by hFMO1 was tested on $\mathrm{N}$-oxidation of Tamoxifen and Soxygenation of Fenthion. The reaction mixture contained: $0.5 \mu \mathrm{M}$ purified enzyme in $0.1 \mathrm{M}$ phosphate buffer $\mathrm{pH} 7.4,0.5 \mathrm{mM} \mathrm{NADPH}$ and different concentrations of each of the two substrates ranging from 0 to $250 \mu \mathrm{M}$. The reaction was initiated by the addition of NADPH and incubated at $37^{\circ} \mathrm{C}$ for $30 \mathrm{~min}$. After this time each reaction was immediately terminated by the addition of $100 \mu \mathrm{l}$ ice-cold acetonitrile. After protein precipitation, each sample was centrifuged at $12000 \times \mathrm{g}$ for $5 \mathrm{~min}$ and the supernatant was analyzed by HPLC.

\subsection{Uncoupling reactions}

Enzymatic reactions were analyzed for: a) the oxidation of $\mathrm{NADPH}, \mathrm{b})$ the formation of the tamoxifen $\mathrm{N}$-oxide product and $\mathrm{c}$ ) the production of $\mathrm{H}_{2} \mathrm{O}_{2}$. Each reaction was prepared in 200 $\mu \mathrm{l}$ total volume of $0.1 \mathrm{M}$ phosphate buffer $\mathrm{pH} 7.4$ in the presence or absence of $100 \mu \mathrm{M}$ 
tamoxifen as substrate, $0.5 \mu \mathrm{M}$ purified $\mathrm{hFMO} 1$ and $0.5 \mathrm{mM} \mathrm{NADPH}$. Reactions were incubated at $37^{\circ} \mathrm{C}$ for either 5 or 30 minutes in the dark. After reaching the required incubation time ( 5 or 30 min.), the reaction mixture was divided into three aliquots to estimate the oxidized NADPH, tamoxifen $\mathrm{N}$-oxide and $\mathrm{H}_{2} \mathrm{O}_{2}$. All experiments were carried out in triplicates.

The amount of consumed NADPH was monitored spectrophotometrically at $340 \mathrm{~nm}$, using 6220 $\mathrm{M}^{-1} \mathrm{~cm}^{-1}$ as extinction coefficient and a sample/buffer dilution of 1:4. To measure the conversion of tamoxifen to tamoxifen $\mathrm{N}$-oxide by $\mathrm{hFMO} 1,100 \mu \mathrm{l}$ of the reaction mixtures were mixed with $50 \mu \mathrm{l}$ of ice-cold acetonitrile to terminate the reaction, centrifuged at $12000 \times \mathrm{g}$ for $5 \mathrm{~min}$ and the supernatant was injected into HPLC to separate and quantify the $\mathrm{N}$-oxide product. The quantification of $\mathrm{H}_{2} \mathrm{O}_{2}$ was carried out using the Amplex Red assay kit (Invitrogen) as previously reported [14] with minor modifications. $50 \mu \mathrm{l}$ of the reaction mixture was heated to $95^{\circ} \mathrm{C}$ for 5 min to terminate the enzymatic reaction. The sample was centrifuged at $12000 \times \mathrm{g}$ for $5 \mathrm{~min}$ and the supernatant was diluted 5 times in the reaction buffer before performing a 1:2 dilution with $50 \mu \mathrm{l}$ of AMPLEX RED mix. Samples were incubated for $5 \mathrm{~min}$ at $25^{\circ} \mathrm{C}$ before analysis. Hydrogen peroxide formation was estimated as a linear function from an absorbance intensity at $570 \mathrm{~nm}$ of resorufin formation.

\subsection{Detection of superoxide by Electron Paramagnetic Resonance (EPR) spectroscopy}

Trapping of superoxide using 5-(Diethoxyphosphoryl)-5-methyl-1-pyrroline-N-oxide (DEPMPO, Enzo Life Sciences) was performed as previously reported [32] with minor modifications. hFMO1 or hFMO3 $(5.3 \mu \mathrm{M})$ was incubated with $6.7 \mathrm{mM}$ NADPH in phosphate-buffered saline (100 mM, pH 7.4) in the presence of $50 \mathrm{mM}$ DEPMPO. To initiate the reaction, the enzyme was added. EPR spectra were recorded at room temperature using a Miniscope 100 EPR spectrometer, (Magnettech, Berlin, Germany). Instrument settings: microwave power $7 \mathrm{~mW}$, 
modulation amplitude $1 \mathrm{G}$, scan time $80 \mathrm{~s}$, two scans. Each incubation with the spin trap was immediately drawn into $50 \mu$ l capillary Ringcaps ${ }^{\circledR}$ (Duran glass, Hirschmann Laborgerate). EPR signal intensities were obtained at 0-20 minutes recording the spectra every 3 minutes. DEPMPO/superoxide adduct had the highest intensity at 6 min. A positive control experiment was carried out with $0.36 \mathrm{mM}$ xanthine and $0.01 \mathrm{U} / \mathrm{ml}$ of xanthine oxidase in $50 \mathrm{mM} \mathrm{KPi}$ buffer $\mathrm{pH} 7.4$ in the presence of $50 \mathrm{mM}$ DEPMPO. The computer simulations of the experimental EPR signals were performed using the WinSim 2002 software (NIH, USA).

\subsection{High-Performance Liquid Chromatography}

The separation and quantitation of the enzymatic reaction products were carried out by HPLC using the commercially available standards of both substrates and their corresponding products (tamoxifen $\mathrm{N}$-oxide and fenthion S-oxide). In each case a standard curve with known concentrations of the products was used. Analysis was performed with an Agilent 1200 quaternary pump HPLC System equipped with a diode array UV detector (Agilent Technologies, USA) with a Kinetex 5 um EVO C18 $100 \AA$ LC column $250 \times 4.6$ mm. Tamoxifen and its metabolite were separated by isocratic elution and were detected at a wavelength of $276 \mathrm{~nm}$. Mobile phase consisted of $82 \%$ of methanol and $18 \%$ of $1 \%$ triethylamine, analysis time was $20 \mathrm{~min}$ with a flow rate of $1.1 \mathrm{ml} / \mathrm{min}$ [33]. Retention time of tamoxifen and its $\mathrm{N}$-oxide product were 6.5 min and 3.5 min, respectively.

Fenthion and its S-oxide product were separated by a gradient elution. In this case the mobile phase consisted of A: acetonitrile and B:10 mM phosphoric acid. Gradient profile was 0-2 min: $A-5 \%, B-95 \% ; 18 \min : A-95 \%, B-5 \% ; 20 \min : A-95 \%, B-5 \% ; 23 \min : A-5 \%, B-$ $95 \% ; 30 \mathrm{~min}: \mathrm{A}-5 \%, \mathrm{~B}-95 \%$. All products were detected at $210 \mathrm{~nm}$ at a flow rate of $1 \mathrm{~mL} / \mathrm{min}$. Retention times of fenthion and its S-oxide were 16.5 min and 12.2 min, respectively. Kinetic 
parameters $\mathrm{K}_{\mathrm{m}}$ and $\mathrm{k}_{\mathrm{cat}}$ were estimated by fitting the data to the Michaelis-Menten equation using OriginPro 2021 software. All experiments were carried out in triplicates and data reported as mean \pm standard deviation.

\section{Results and Discussion}

Wild-type human FMO1 was expressed in E. coli and purified as outlined in the methods section. The structural integrity and folding of the pure protein were estimated by the circular dichroism (Figure 1). The fitting of the obtained spectra by the $\beta$-structure selection (BeStSel) algorithm [31] allowed to predict hFMO1 secondary structure content leading to a $37 \%$ alpha helical content in agreement with previously published data for the human FMO family $[27,28]$. The functionality of the enzyme was studied measuring its catalytic behaviour using three different substrates capable of generating either $\mathrm{N}$ - or S-oxidised products: hypotaurine (physiological substrate [24]), tamoxifen (anti-cancer drug [34]) and fenthion (pesticide [35]). The chemical structures of these different substrates are shown in Figure 2 together with the corresponding monooxygenated products.

Kinetic parameters for the reaction of each of the selected substrates was determined at $37^{\circ} \mathrm{C}$ in the presence of NADPH as the reducing cofactor and in $\mathrm{pH}$ 7.4. Kinetic parameters for the conversion of hypotaurine were estimated by NADPH consumption assay as previously reported [26], with a $K_{m}$ of $31.9 \pm 6.4 \mu \mathrm{M}$ and $k_{\text {cat }}$ value of $0.41 \mathrm{~s}^{-1}$. The $\mathrm{K}_{\mathrm{m}}$ value is different to already published value of $4.1 \mathrm{mM}$ however the $\mathrm{k}_{\text {cat }}$ is very similar [26]. For tamoxifen and fenthion the $\mathrm{K}_{\mathrm{m}}$ values were calculated from the amount of product determined by HPLC analysis and were $114.1 \pm 17.7$ and $178.3 \pm 46.6 \mu \mathrm{M}$ and $k_{\text {cat }}$ of 0.21 and $0.25 \mathrm{~s}^{-1}$, respectively. These kinetic data are in line with previously published values [34,35], confirming the structural as well as functional integrity of the enzyme. 
Recent findings on hFMO3 have highlighted the key role of $\mathrm{NADP}^{+}$in stabilizing the protein structure, measured as a significant shift of the melting temperature $\left(T_{m}\right)$ from $45.1 \pm 0.1^{\circ} \mathrm{C}$ to the higher value of $49.1 \pm 0.2{ }^{\circ} \mathrm{C}$ [9]. For this reason, we followed the unfolding of hFMO1 in the absence and in the presence of $\mathrm{NADP}^{+}$or $\mathrm{NAD}^{+}$using differential scanning calorimetry (DSC) and the results are shown in Figure 3. As can be seen in the figure, in the absence of either cofactor (black line) a $\mathrm{T}_{\mathrm{m}}$ of $40.8 \pm 0.2^{\circ} \mathrm{C}$ is measured. Addition of $0.5 \mathrm{mM} \mathrm{NADP}^{+}$causes a shift of the $\mathrm{T}_{\mathrm{m}}$ to $47.5 \pm 0.1{ }^{\circ} \mathrm{C}$ (red line) with an unfolding process starting at higher temperatures (above $34^{\circ} \mathrm{C}$ ). On the other hand, when $\mathrm{NAD}^{+}$is added no significant change is detected in $T_{m}$ (green line) in comparison to the protein in the absence of cofactor.

As these data do not exclude a possible role of $\mathrm{NAD}^{+}$in $\mathrm{FMO} 1$ catalysis, the ability of the enzyme to use both NADH or NADPH as source of reducing unit was investigated. Since pH 7.4 represents a physiological benchmark and for hFMO1 it has been previously reported that both cofactors are equally effective for catalysis at this $\mathrm{pH}$ [26], all experiments were conducted at $\mathrm{pH} 7.4$.

Indeed, steady-state measurements based on Michaelis-Menten plots, show that the $\mathrm{K}_{\mathrm{m}}$ value for NADH is slightly higher than the one for NADPH (Table 1), indicating a lower affinity for $\mathrm{NADH}$. Some differences are observed in the $k_{c a t}$ values and also the resulting $k_{c a t} / K_{m}$ ratios (Table1), taken together suggesting the preference of hFMO1 for NADPH.

Furthermore, in order to assess the significance of this preference, pre-steady state conditions were used to measure the rate of reduction of the enzyme by NADH and NADPH. To this end stopped-flow experiments were carried out using NADPH at different concentrations while monitoring the reduction rate of the flavin at $450 \mathrm{~nm}$ in anaerobiosis. Fitting the data resulted in a binding rate $\left(k_{d}\right)$ of $4.79 \pm 0.38 \mathrm{~s}^{-1}$ and a reduction rate $\left(k_{\text {red }}\right)$ of $0.78 \pm 0.01 \mathrm{~s}^{-1}$ (Figure 4A). 
The hyperbolic behaviour shown in Figure 4A indicates a single irreversible hydride transfer step with no other spectral changes at higher wavelengths.

The same experiments were carried out under the same conditions using NADH as the reductant. Data analysis in this case resulted in a $k_{\text {red }}$ of $1.20 \pm 0.03 \mathrm{~s}^{-1}$ and a $\mathrm{k}_{d}$ of $468.65 \pm$ $30.38 \mathrm{~s}^{-1}$ (Figure 4B).

Data from this reductive step clearly indicates that $\mathrm{hFMO} 1$ can be reduced much more efficiently by NADPH. For this reason, experiments on the subsequent oxidation step in the presence of molecular oxygen were carried out only with NADPH.

Reduced hFMO1 was rapidly mixed with oxygenated buffer, and the formation and decay of the C4a-hydroperoxyflavin intermediate was followed at $368 \mathrm{~nm}[23,28]$. Moreover, the effect of the presence of the substrate on the re-oxidation process was investigated in the absence and presence of the substrate hypotaurine. Figure $5 \mathrm{~A}$ and $\mathrm{B}$ show the spectral features of the reduced hFMO1 (black line), the C4a-hydroperoxyflavin intermediate formation (red line) and the re-oxidised species (green line) in absence and presence of hypotaurine, respectively. It can be observed from the spectra that the C4a-hydroperoxyflavin intermediate builds up rapidly (within 2-3 seconds), but decays at a slow rate leading to the oxidised FAD.

Kinetic data following the re-oxidation of the flavin to its ground state were collected measuring the absorbance increase at $450 \mathrm{~nm}$ (Figure 5C). The kinetic traces clearly demonstrate that the substrate hypotaurine accelerates the re-oxidation process which is completed in less than 200 seconds (black trace). On the other hand, in the absence of the substrate, even at 1750 seconds the enzyme is not fully re-oxidised (red trace).

Overall the stopped-flow data indicate that hFMO1 C4a-hydroperoxyflavin intermediate is very stable and full re-oxidation can only be observed in the presence of the substrate. This is in keeping with previously published data suggesting that the presence of the substrate has a 
destabilising effect on the C4a-hydroperoxyflavin leading to an increase in the rate of reoxidation of the flavin [24].

Rates for the flavin re-oxidation, intermediate formation and decay all highlight significant differences in the behaviour of hFMO1 when compared to previously reported data on $\mathrm{hFMO} 3$ [9] and AncFMO3-6 (a soluble synthetic protein based on ancestral reconstruction of FMO isoforms 3-6) [36] as shown in Table 2. On the other hand, the remarkable stability of intermediate of hFMO1 (around $30 \mathrm{~min}$ at $15^{\circ} \mathrm{C}$ ) is in line with what was reported for pig liver FMO1 where this was found to last for hours at $4{ }^{\circ} \mathrm{C}[11]$.

Since the stopped-flow data point to a stable FAD intermediate we decided to also measure the levels of uncoupling in purified hFMO1 enzyme. Previous data using baculovirus expressing hFMO1 have indicated that this enzyme is highly uncoupled producing $40-50 \%$ of $\mathrm{H}_{2} \mathrm{O}_{2}$ [13]. The same researchers also found that the addition of substrate did not significantly alter the amount of $\mathrm{H}_{2} \mathrm{O}_{2}$ being formed [13]. No uncoupling data on purified hFMO1 are currently available but purified $\mathrm{hFMO} 3$ was found to be $50-70 \%$ uncoupled when benzydamine is used as substrate [14]. Whereas the high levels of uncoupling seen in $\mathrm{hFMO} 3$ match the intrinsic instability of its own intermediate [9], the data on baculovirus expressing hFMO1 is not in line with the remarkable stability of the C4a-hydroperoxyflavin intermediate published for purified pig FMO1 [6]. In addition, the data presented here on the stability of the purified hFMO1 intermediate is also contrary to the baculovirus expressing hFMO1. For this reason, the uncoupling reactions of purified hFMO1 were investigated by initially measuring $\mathrm{H}_{2} \mathrm{O}_{2}$ production. For the coupled reaction tamoxifen was selected as substrate because hFMO1 is known to catalyse its conversion to tamoxifen $\mathrm{N}$-oxide. To maximize the comparability of the data NADPH oxidation, tamoxifen $\mathrm{N}$-oxidation and hydrogen peroxide were measured from the same reaction mixture. NADPH oxidation was quantified by monitoring the decrease in 
absorbance at $340 \mathrm{~nm}$, the amount of $\mathrm{H}_{2} \mathrm{O}_{2}$ produced was measured by mixing aliquots of each reaction with the AMPLEX red kit components, whereas the amount of tamoxifen $\mathrm{N}$-oxide was calculated by HPLC analysis. The results are obtained are shown in Figure 6A. In the absence of substrate, $0.5 \mu \mathrm{M}$ of hFMO1 consumes $3.3 \mu \mathrm{M}$ of $\mathrm{NADPH}$ after 30 minutes of reaction, whereas the amount of $\mathrm{H}_{2} \mathrm{O}_{2}$ produced is $2.8 \mu \mathrm{M}$, respectively. This data indicates that very little NADPH is consumed by hFMO1 in the absence of substrate. On the other hand, in the presence of substrate, $0.5 \mu \mathrm{M}$ of hFMO1 consumes $\sim 93 \mu \mathrm{M}$ of NADPH in 30 minutes of reaction, whereas the amount of $\mathrm{H}_{2} \mathrm{O}_{2}$ produced is $\sim 0.9 \mu \mathrm{M}$ respectively (Figure 6). Indeed, $\mathrm{NADPH}$ consumption is almost 30 times higher in the presence of substrate indicating a strong coupling effect driven by tamoxifen. Furthermore, when the uncoupling is evaluated as the ratio of $\mathrm{H}_{2} \mathrm{O}_{2} / \mathrm{NADPH}$ it is as low as $1 \%$ (Fig.6B).

Contrary to the published data on the hFMO3 uncoupling, the unproductive shorter cycle leading to $\mathrm{H}_{2} \mathrm{O}_{2}$ leakage is a neglectable phenomenon for $\mathrm{hFMO} 1$ because the enzyme is highly coupled and it does not waste the reducing equivalents of NADPH unless a suitable substrate gains access to its active site. These data are fully in line with the stopped-flow data presented earlier with the purified enzyme where the half-life of the C4a-hydroperoxyflavin is found to be reasonably long and strongly influenced by the presence of the substrate.

Previously published data have indicated that hFMO3 forms not only hydrogen peroxide but to a lesser extent also the superoxide radical anion as the result of its uncoupling reactions [14]. In order to prove the different behaviour of hFMO1 compared to hFMO3 and confirm the higher overall coupling of hFMO1, EPR spectroscopy experiments were carried out to detect the formation of any superoxide radical anion using the spin trap DEPMPO. The latter compound has a long-lived superoxide radical anion adduct (DEPMPO-OOH) with a half-life of $14.8 \mathrm{~min}$ $[32,37]$. EPR experiments were carried out with both purified hFMO1 and hFMO3 in the 
presence of large excess of NADPH and DEPMPO. The data are shown in Figure 7. As can be seen in Figure 7A, no EPR signal was observed for the hFMO1 reaction whereas hFMO3 displayed the typical spectrum of DEPMPO-OOH adduct with a maximum signal reached after 6 minutes of incubation with the spin trap (Figure 7B). As a positive control for visualisation of the superoxide DEPMPO adduct, xanthine/xanthine oxidase system was used since the EPR spectra of their DEPMPO-OOH adduct is already published $[32,37]$ and the results are shown in Figure $7 \mathrm{C}$. The simulated spectrum of xanthine oxidase was also used for calculating the coupling constants of DEPMPO-OOH adduct that are summarized in Table 3 and are comparable to previous literature reports [37].

\section{Concluding Remarks}

Human FMOs have not been studied in depth mainly due to the difficulties in producing the folded and active forms of the different isoforms of the enzyme. In this work, hFMO1 has been successfully purified after heterologous expression in $E$. coli in its folded and active form and this allowed to follow its catalytic cycle including its reduction and re-oxidation steps. After the initial stopped-flow experiments of Beaty and Ballou more than 40 years ago which led to the identification of the important intermediate in the catalytic cycle of these flavo-enzymes, C4ahydroperoxyflavin [11], this intermediate has been captured for the first time in human FMO1 in the current work using the same methodology. The data demonstrate that human FMO1 differs from human FMO3 because it forms a more stable C4a-hydroperoxy intermediate that constitutes the basis for understanding the catalytic properties of this specific isoform.

Furthermore, since the stability of this intermediate results in a higher coupling of the enzyme reactions this means that, unlike human $\mathrm{FMO}$, the FMO1 is a more coupled enzyme. This was also proven experimentally by measuring the amounts of ROS produced by this enzyme; 
$\mathrm{hFMO} 1$ is $<5 \%$ uncoupled compared to $50 \%$ hFMO3. Moreover, using EPR spin trapping experiments we further demonstrate that $\mathrm{hFMO} 3$ forms also the superoxide anion radical whereas no superoxide-adduct was observed for hFMO1.

Although hFMO1 and its enzymatic reactions have not been as extensively studied as the hFMO3, the kinetic as well as catalytic data presented here, demonstrate the different enzymatic behaviours of these two closely related human enzymes.

\section{Author Contributions}

Conceptualisation and methodology, G.G. and S.J.S.; formal analysis, H.C. and G.C.; investigation, H.C., A.M. and G.C.; resources, G.G. and S.J.S.; data curation, H.C., G.C. and I.F. (EPR); writing—original draft preparation, H.C., G.C. and S.J.S.; writing—review and editing, G.G. and S.J.S.; supervision, S.J.S.; funding acquisition, S.J.S.

\section{Conflicts of interest}

The authors declare no conflict of interest.

\section{Acknowledgement}

Hanna Cheropkina is the recipient of a three-year $\mathrm{PhD}$ scholarship from University of Torino awarded to international students. 


\section{References}

1 Cytochrome P450: Structure, mechanism and biochemistry. Fourth Edition. Ortiz de Montellano (Ed.), Springer, 2015.

2 Ziegler, D. M. Drug Metab Rev., 2002, 34, 503-511.

3 J. R. Cashman and J. Zhang, Annu. Rev. Pharmacol. Toxicol., 2006, 46, 65-100.

$4 \quad$ I. R. Philips and E. A. Shephard, Catalysts, 2019, 9,1001.

5 J. Rittle and M. Green, Science, 2010, 330, 933-937.

6 S. Nagano, J. R. Cupp-Vickery and T. L. Poulos, J. Biol. Chem., 2005, 280, 2210222107.

$7 \quad$ I. Schlichting et al., Science, 2000, 287, 1615-1622.

8 R. Orru, D. E. T. Pazmino, M. W. Fraaije and A. Mattevi, J. Biol. Chem., 2010, 285, $35021-35028$.

9 C. Gao, G. Catucci, S. Castrignanò, G. Gilardi and S. J. Sadeghi, Sci Rep, 2017, 7, 14668.

10 N. B. Beaty and D. P. Ballou, J. Biol. Chem., 1981, 256, 4611-4618.

11 N. B. Beaty and D. P. Ballou, J. Biol. Chem., 1981, 256, 4619-4625.

12 K. C. Jones and D. P. Ballou, J. Biol. Chem., 1986, 261, 2553-2559.

13 L. K. Siddens, S. K. Krueger, M. C. Henderson and D. E. Williams, Biochem. Pharm., $2014,89,141-147$.

14 G. Catucci, C. Gao, G. Rampolla, G. Gilardi and S. J. Sadeghi, Free Radic Biol. Med., $2019,145,250-255$.

15 E. J. Rauckman, G. M. Rosen, and B. B. Kitchell, Mol. Pharmacol., 1979, 15, 131-137.

16 J. Zhang and J. R. Cashman, Drug Metab Dispos., 2006, 34, 19-26.

17 I. R. Phillips and E. A. Shephard, Trends Pharmacol Sci, 2008, 29, 294-301. 
R. N. Hines, Expert Opin Drug Metab Toxicol., 2006, 2, 41-49.

I. R. Phillips, C. T. Dolphin, P. Clair, M. R. Hadley, A. J. Hutt, R. R. McCombie, R. L. Smith and E. A. Shephard, Chem Biol Interact, 1995, 96, 17-32.

S.B. Koukouritaki, R.N. Hines, 2005, Pharmacogen, 6, 807-822.

21 G. Catucci, A. Occhipinti, M. Maffei, G. Gilardi, S.J. Sadeghi, 2013, Int. J. Mol. Sci. 14, 2707-2716.

22 G. L. Rosano and E. A. Ceccarelli, Front Microbiol, 2014, 5, 172.

23 G. Catucci, S. J. Sadeghi and G. Gilardi, Chem Commun (Camb), 2019, 55, 6217-6220.

24 L. L. Poulsen and D. M. Ziegler, Chemico-Biological Interactions, 1995, 96, 57-73.

25 G. Catucci, D. Aramini, S. J. Sadeghi and G. Gilardi, Int J Biol Macromol, 2020, 162, 1484-1493.

26 S. Veeravalli, I. R. Phillips, R. T. Freire, D. Varshavi, J. R. Everett and E. A. Shephard, Drug Metab Dispos, 2020, 48, 378-385.

27 G. Catucci, G. Gilardi, L. Jeuken and S. J. Sadeghi, Biochem. Pharmacol., 2012, 83, 551-558.

28 G. Bailleul, C. R. Nicoll, M. L. Mascotti, A. Mattevi, M. W. Fraaije, J Biol Chem, 2021, 296, 100221.

29 J. Dong and T. D. Porter, Arch Biochem and Biophys, 1996, 327, 254-259.

30 S.J. Sadeghi, R. Meirinhos, G. Catucci, V.R. Dodhia, G. Di Nardo, G. Gilardi, J. Am. Chem. Soc., 2010, 132, 458-459.

31 A. Micsonai, F. Wien, É. Bulyáki, J. Kun, É. Moussong, Y. H. Lee, Y. Goto, M. Réfrégiers, J. Kardos, Nucleic Acids Res., 2018, 46, W315-W322.

32 H. Shi, G. Timmins, M. Monske, A. Burdick, B. Kalyanaraman, Y. Liu, J.-L. Clément, S. Burchiel and K. J. Liu, Arch Biochem Biophys, 2005, 437, 59-68. 
33 S. Bortolussi, G. Catucci, G. Gilardi and S. J. Sadeghi, Arch. Biochem. Biophys., 2021, 697, 108663.

34 S. K. Krueger, J. E. VanDyke, D. E. Williams and R. N. Hines, Drug metab. reviews, 2006, 38, 139-147

35 B. Furnes and D. Schlenk, Toxicol Sci, 2004, 78, 196-203.

36 C. R. Nicoll, G. Bailleul, F. Fiorentini, M. L. Mascotti, M. W. Fraaije and A. Mattevi, Nat Struct Mol Biol, 2020, 27, 14-24.

37 C. Frejaville, H. Karoui, B. Tuccio, F. Le Moigne, M. Culcasi, S. Pietri, R. Lauricella, P. Tordo, J. Med. Chem. 1995, 38, 258-265. 


\section{Table 1}

Table 1. Steady-state kinetic parameters of the NADPH and NADH oxidation by hFMO1 at $\mathrm{pH} 7.4$

\begin{tabular}{lccc}
\hline Ligand & $\mathbf{K}_{\mathbf{m}},[\mu \mathbf{M}]$ & $\mathbf{k}_{\text {cat }},\left[\mathbf{s}^{-1}\right]$ & $\mathbf{k}_{\text {cat }} / \mathbf{K}_{\mathbf{m}},\left[\mathbf{s}^{-1} / \mathbf{M}\right]$ \\
\hline NADPH & $83.5 \pm 9$ & 0.19 & 2356 \\
NADH & $106.6 \pm 10$ & 0.24 & 2258 \\
\hline
\end{tabular}




\section{Table 2}

Table 2 Kinetic parameters of hFMO1 re-oxidation half-reactions

\begin{tabular}{|c|c|c|c|c|}
\hline \multirow{2}{*}{ Protein } & \multicolumn{2}{|c|}{$\begin{array}{l}\text { FAD Intermediate } \\
\qquad(368 \mathrm{~nm})\end{array}$} & \multirow{2}{*}{$\begin{array}{c}\begin{array}{c}\text { Re-oxidation } \\
(450 \mathrm{~nm})\end{array} \\
\mathbf{k}_{\text {decay }} \\
{\left[\mathbf{s}^{-1}\right]}\end{array}$} & \multirow[t]{2}{*}{ Reference } \\
\hline & $\begin{array}{l}\mathbf{k}_{\text {formation }} \\
{\left[\mathbf{s}^{-1}\right]}\end{array}$ & $\begin{array}{l}k_{\text {ox }} \\
{\left[\mathbf{s}^{-1}\right]}\end{array}$ & & \\
\hline $\begin{array}{l}\text { hFMO1 (without } \\
\text { substrate) }\end{array}$ & 1.383 & $\begin{array}{l}R_{1}=0.01429 \\
R_{2}=0.00086\end{array}$ & $<0.00001$ & present work \\
\hline $\begin{array}{l}\text { hFMO1 (with } \\
\text { Hypotaurine) }\end{array}$ & 1.768 & $\begin{array}{l}R_{1}=0.02214 \\
R_{2}=0.00312\end{array}$ & 0.0001 & present work \\
\hline $\begin{array}{l}\text { hFMO3 } \\
\text { (without } \\
\text { substrate) }\end{array}$ & 1.580 & $\begin{array}{l}\mathrm{R}_{1}=0.790 \\
\mathrm{R}_{2}=0.0009\end{array}$ & 0.001 & [28] \\
\hline AncFMO3-6 & 3.7 & N/D & 0.01 & [36] \\
\hline
\end{tabular}




\section{Table 3}

Table 3. Coupling constants of the DEPMPO-OOH adduct.

\begin{tabular}{lllll}
\hline Conformer & AP & AN & Ah $\boldsymbol{B}$ & AHy \\
\hline trans 1 (94\%) & 48.92 & 12.80 & 10.81 & 0.87 \\
trans 2 (6\%) & 40.27 & 13.57 & 8.22 & 0.81 \\
\hline
\end{tabular}




\section{Figure legends}

Figure 1. Circular Dichroism of purified FMO1: Spectrum of overall fold of the protein at $25^{\circ} \mathrm{C}$ in $0.1 \mathrm{M}$ phosphate buffer $\mathrm{pH} 7.4$.

Figure 2. Chemical structures of the three substrates of hFMO1 together with the enzymatic products. The site of $\mathrm{N}$ - or S-oxidation is highlighted in red.

Figure 3. DSC data of hFMO1. The scan of protein without ligand is shown in black, in the presence of $0.5 \mathrm{mM} \mathrm{NADP}^{+}$in red and with $0.5 \mathrm{mM} \mathrm{NAD}^{+}$in green. Measurements were carried out in $0.1 \mathrm{M}$ phosphate buffer $\mathrm{pH} 7.4$.

Figure 4. Pre-steady-state analysis of the hFMO1 reductive half-reaction. Hyperbolic fitting of the plots for (A) NADPH and (B) NADH. Measurements were carried out in $0.1 \mathrm{M}$ phosphate buffer $\mathrm{pH} 7.4$ at $15^{\circ} \mathrm{C}$.

Figure 5. Oxidative half-reaction. The re-oxidation spectra of NADPH reduced hFMO1 in the presence of oxygenated buffer. Selected spectra showing reduced (black), intermediate (red) and re-oxidized flavin (green). (A) Traces in the absence and (B) in the presence of hypotaurine. (C) Comparison of the re-oxidation rates monitored at $450 \mathrm{~nm}$ in the absence (red dots) and in the presence (black dots) of hypotaurine. Measurements were carried out in $0.1 \mathrm{M}$ phosphate buffer $\mathrm{pH} 7.4$ at $15^{\circ} \mathrm{C}$. 
Figure 6. Uncoupling measurements of hFMO1: A) $\mathrm{H}_{2} \mathrm{O}_{2}$ (blue), $\mathrm{NADP}^{+}$(red) and tamoxifen $\mathrm{N}-$ oxide formation (black) in the absence or presence of the substrate tamoxifen after 30 minutes of reaction. B) Comparison of the uncoupling reactions of $\mathrm{hFMO1}$ and $\mathrm{hFMO3.} \%$ uncoupling calculated as $\mathrm{H}_{2} \mathrm{O}_{2} / \mathrm{NADPH}$ oxidized by each enzyme in the presence of substrate after 5 or 30 minutes of reaction.

Figure 7 Representative EPR spectra of superoxide radical anion adducts of DEPMPO with either $(\mathrm{A}) \mathrm{hFMO1}$ or $(\mathrm{B}) \mathrm{hFMO3}$ reaction taken at three different time points. $50 \mathrm{mM}$ DEPMPO was incubated with $5.3 \mu \mathrm{M} \mathrm{hFMO}$ and $6.6 \mathrm{mM} \mathrm{NADPH}$ in $50 \mathrm{mM} \mathrm{KPi} \mathrm{pH} \mathrm{7.4.} \mathrm{(C)} \mathrm{EPR} \mathrm{spectra}$ of DEPMPO-OOH of the reactions of a) hFMO3; b) Xanthine oxidase; c) computer simulated spectrum of (b). 
Figure 1

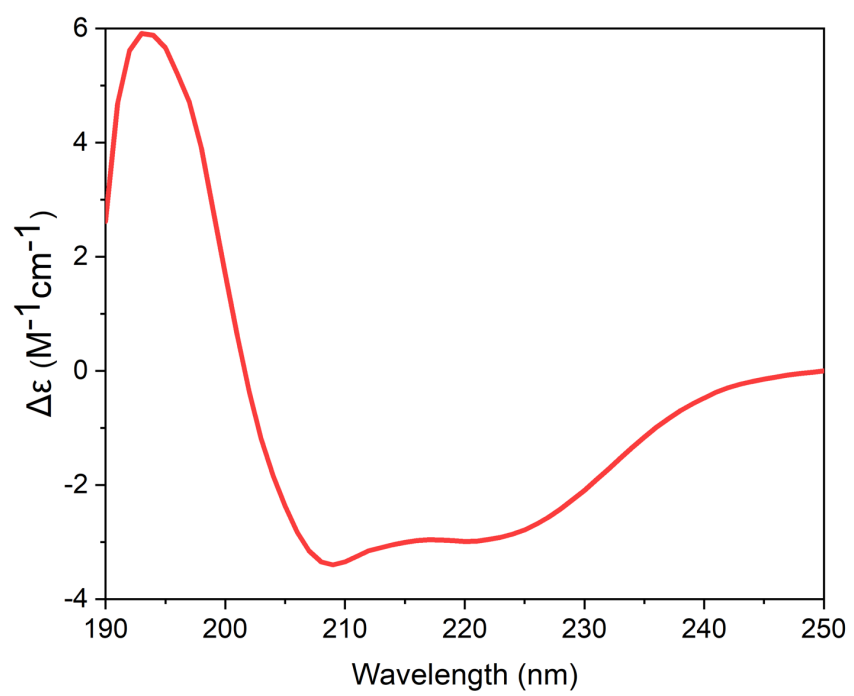


Figure 2

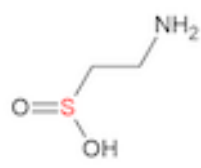

Hypotaurine

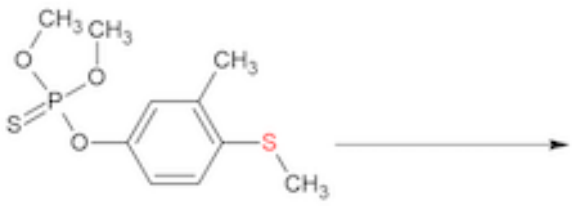

Fenthion

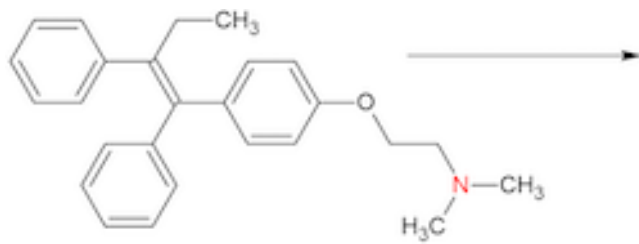

Tamoxifen

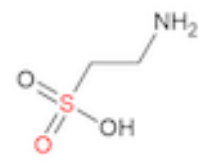

Taurine

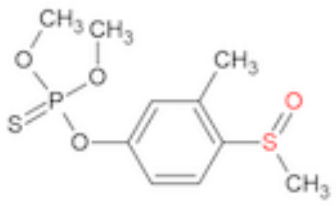

Fenthion S-oxide

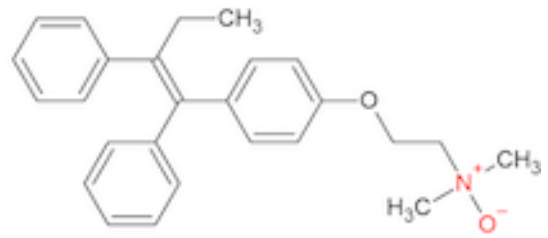

Tamoxifen $\mathrm{N}$-oxide 
Figure 3

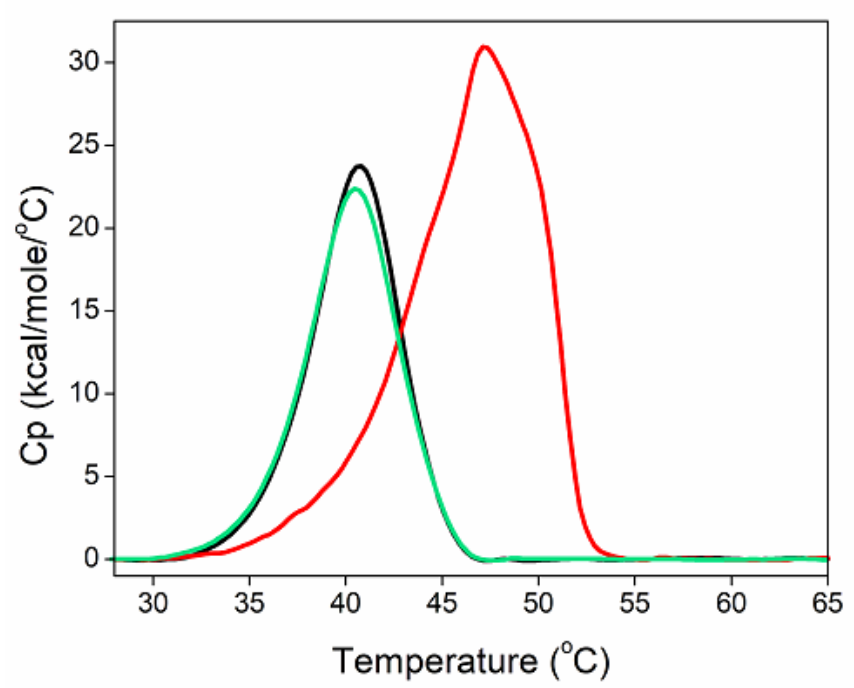


Figure 4
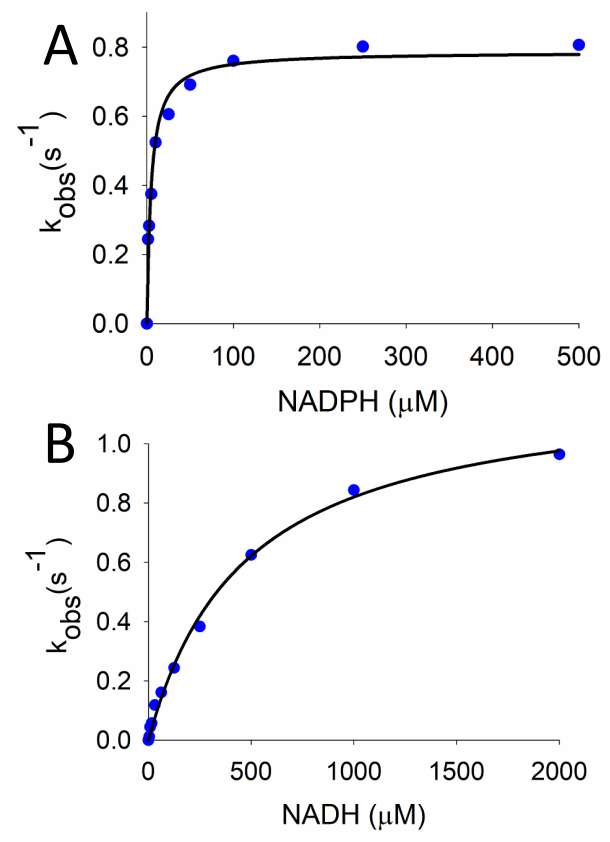
Figure 5
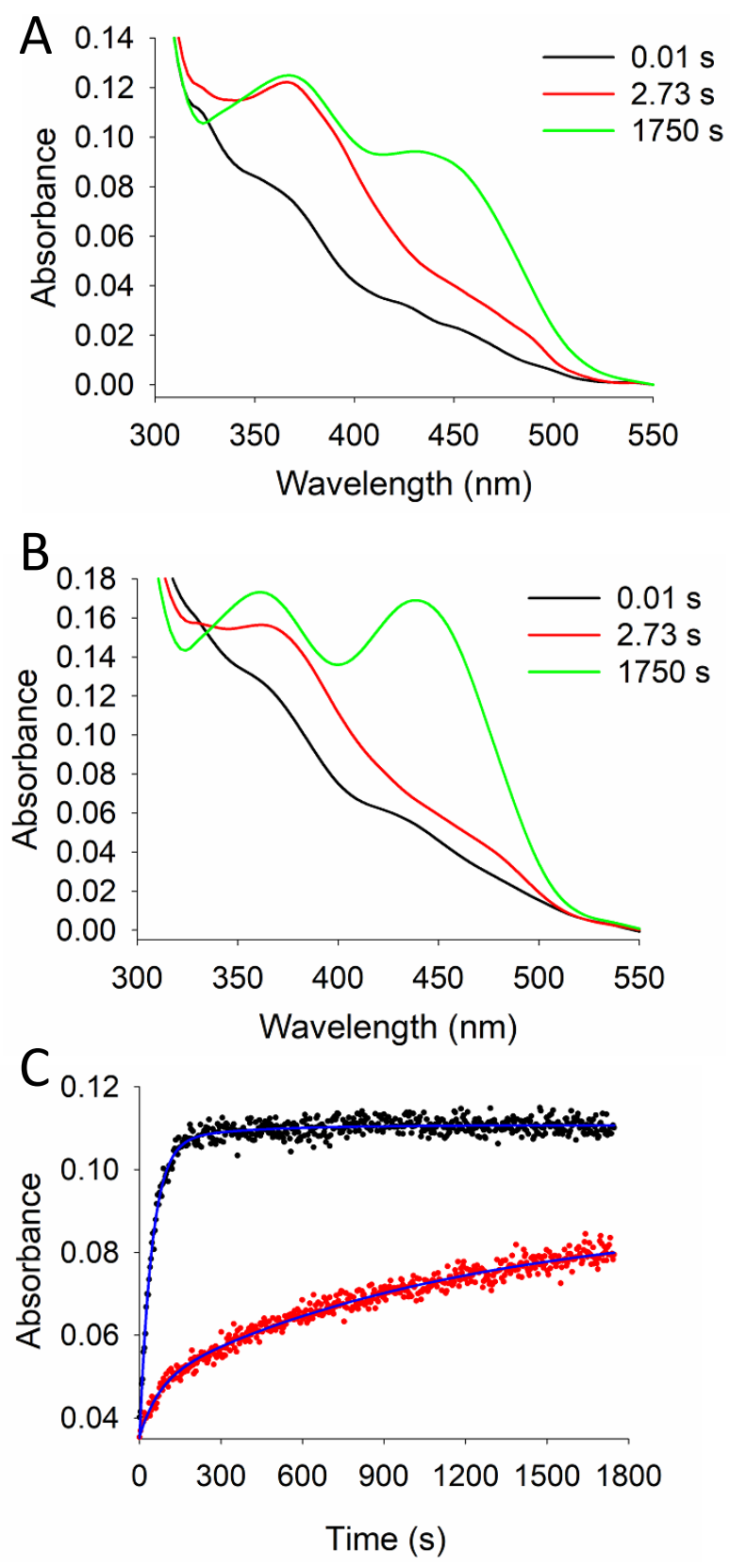
Figure 6

A)

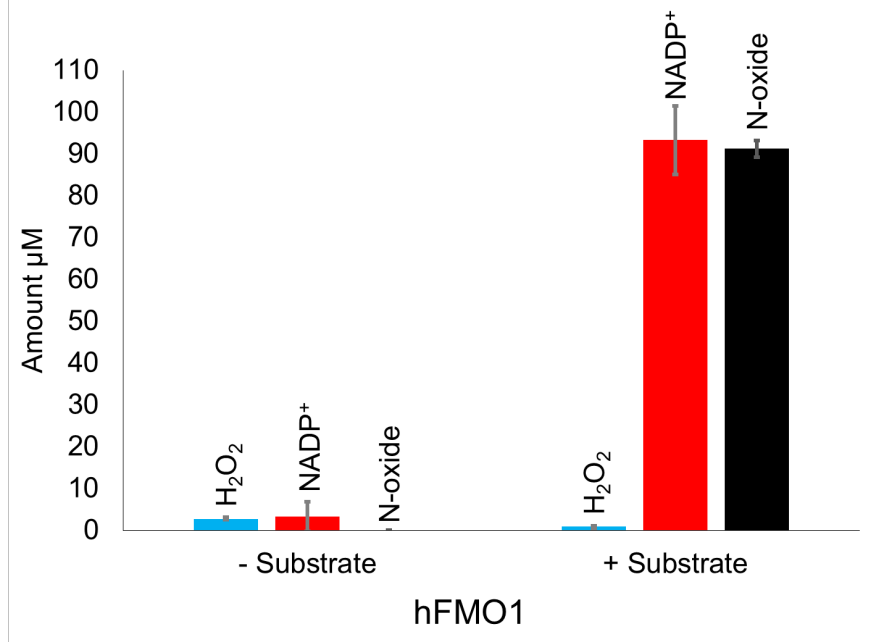

B)

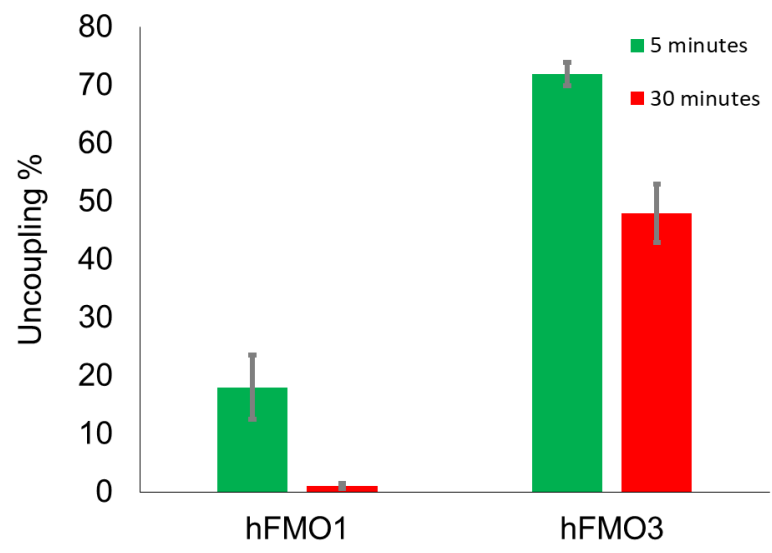


Figure 7

A

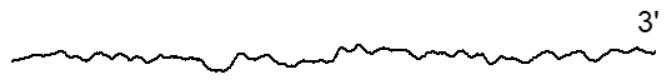

0
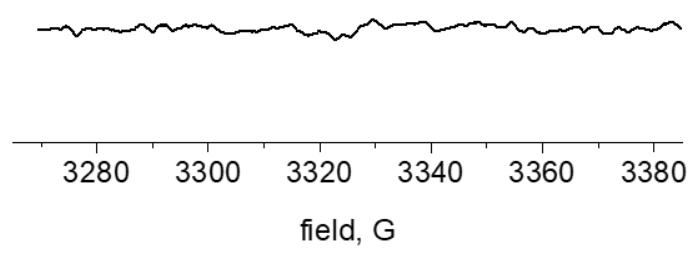

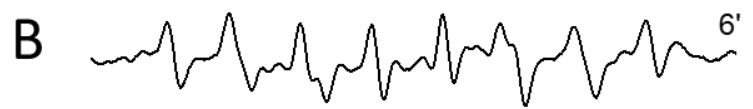
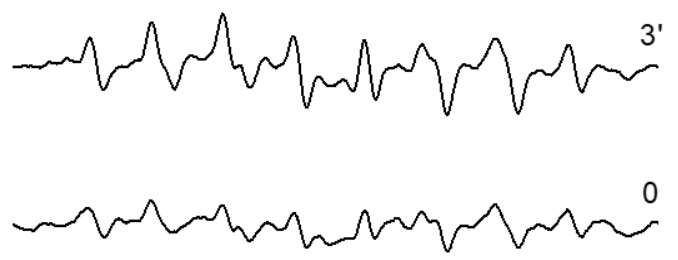

\begin{tabular}{|c|c|c|c|c|c|}
\hline 3280 & 3300 & 3320 & 3340 & 3360 & 3380 \\
\hline
\end{tabular}

5000A.U.
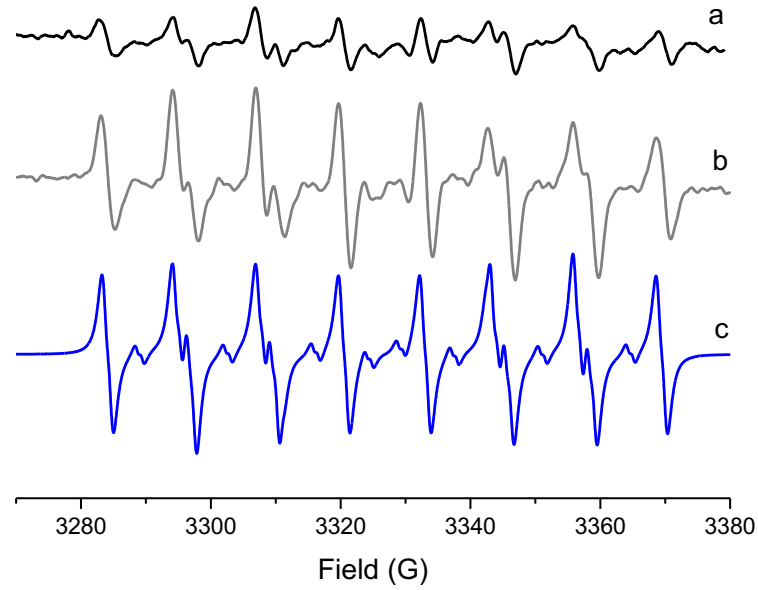